\title{
Breast metastasis from vaginal cancer
}

\author{
Neeraja Chandrasekaran, ${ }^{1}$ Daniel Scharifker, ${ }^{2}$ George Varsegi, ${ }^{2}$ Zoyla Almeida ${ }^{3}$
}

${ }^{1}$ Cleveland Clinic Florida, Weston, Florida, USA ${ }^{2}$ Department of Pathology, West Boca Medical Center Boca Raton, Florida, USA ${ }^{3}$ Department of Gynecologic Oncology, West Boca Medical Center, Boca Raton, Florida, USA

\section{Correspondence to} Dr Neeraja Chandrasekaran, mdneeruthimma@gmail.com

Accepted 6 July 2016
CrossMark

To cite: Chandrasekaran N,
Scharifker D, Varsegi G,
et al. BMJ Case Rep
Published online: [please
include Day Month Year]
doi:10.1136/bcr-2016-
215895

To cite: Chandrasekaran $\mathrm{N}$, Scharifker D, Varsegi $G$ et al. BMJ Case Rep Published online: [please 215895

\begin{abstract}
SUMMARY
Vaginal cancer is a rare malignancy accounting for $1-2 \%$ of all pelvic neoplasms. Dissemination usually occurs through local invasion and rarely metastasises to distal locations. Metastasis of vaginal cancer to the breast is extremely infrequent and unique. A 66-year-old Asian woman presented with vaginal bleeding and was found to have a vaginal mass and a left breast mass. Pathological assessment of the biopsies revealed identical squamous cell characteristics of both masses. We describe a very rare and novel case of a distally located vaginal carcinoma with metastasis to the breast Federation of Gynecology and Obstetrics (FIGO) stage IV (FIGO IVB). Robot-assisted extrafascial total hysterectomy with local vaginal mass excision and partial mastectomy of the left breast were performed. After surgery, the patient underwent adjuvant chemotherapy followed by breast and pelvic radiotherapy, with maintained complete remission after 3 years of follow-up. This combination of findings and treatment is very distinct with a unique and favourable response.
\end{abstract}

\section{BACKGROUND}

Vaginal carcinomas are rare malignancies, accounting for $1-2 \%$ of all pelvic neoplasms in women. ${ }^{1}$ These tumours are locally invasive and occasionally metastasise haematologically to the lung, liver, bone and skin. ${ }^{2}{ }^{3}$ Metastasis of vaginal carcinoma to the breast is extremely rare and has not been reported to the best of our knowledge.

\section{CASE PRESENTATION}

A 66-year-old Asian woman with a history of diabetes mellitus, hypertension, dyslipidaemia, chronic renal insufficiency, and morbid obesity presented to the emergency room with symptoms of vaginal bleeding for 3 days. She denied history of vaginal irritation, radiation exposure, diethylstilbestrol exposure and multiple sexual encounters. She was unclear regarding her human papilloma virus (HPV) status. Surgical history was reviewed and was unremarkable. She denied history of smoking or alcohol consumption. Family history was reviewed and was positive for her brother who had stage IV colon cancer at 68 years. Review of symptoms was positive for a generalised malaise. Physical examination revealed morbid obesity (body mass index $49.8 \mathrm{~kg} / \mathrm{m}^{2}$ ), pallor and a $5 \mathrm{~cm}$ lump/nodule in her left breast, which she had noticed for the past 2 months but did not seek care, and a $3 \mathrm{~cm}$ friable mass on the lower third of the vagina. Vulvar and inguinal examinations were normal. She had not sought any gynaecological care for the past 15 years, hence prior pap smear and mammogram reports were unavailable.

\section{INVESTIGATIONS}

Mammography revealed a suspicious left breast mass and a transvaginal ultrasound was performed which revealed slightly increased endometrial thickness $(8 \mathrm{~mm})$. Pap smear was negative. She was then scheduled for endometrial, vaginal and left breast biopsy. The endometrial biopsy performed by hysteroscopy was negative for malignancy. The vaginal mass was biopsied and found to be positive for an invasive, poorly differentiated squamous cell carcinoma (SCC). Immunohistochemical (IHC) studies performed on the vaginal mass demonstrated poorly differentiated SCC with high proliferative activity and HPV subtype 16 positive (figure 1). Core biopsy of the left breast mass was performed and revealed identical characteristics and IHC studies were consistent with the vaginal mass (figure 2), and negative for estrogen receptor, progesterone receptor, and Herceptin receptor 2 (ER/PR and HER2). A full-body positron emission tomography (PET) scan was also performed which

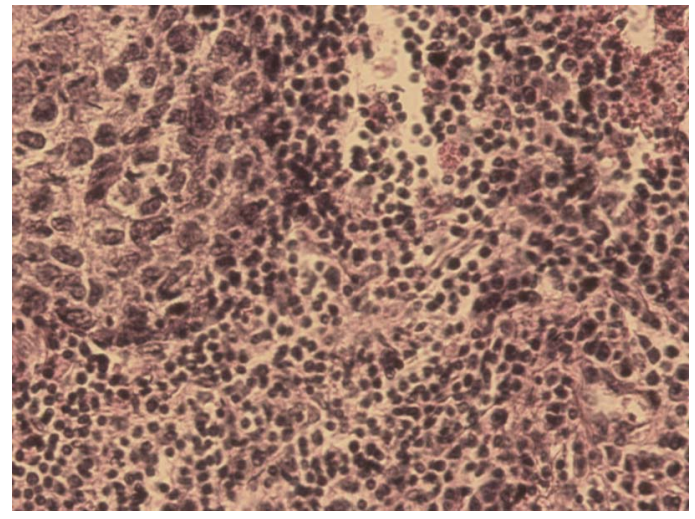

Figure 1 Pure squamous cell vaginal cancer, identical to the breast mass.

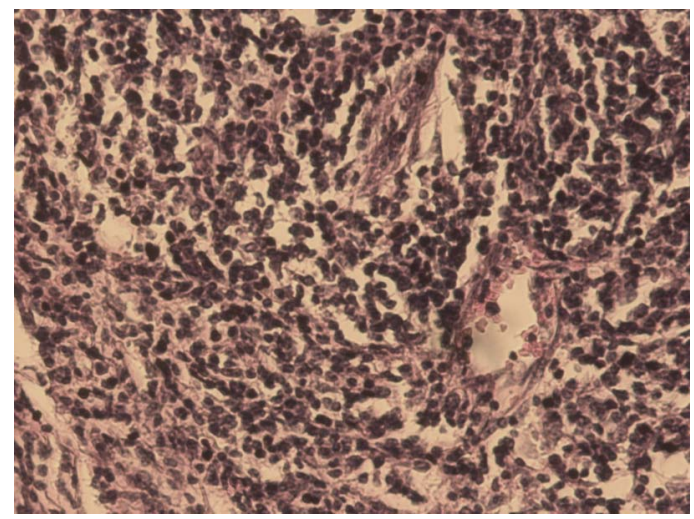

Figure 2 Pure squamous cell cancer of the breast, identical to the vaginal mass. 
revealed intense hypermetabolic activity in the left breast (figures 3-5) and vagina (figures 6-8), excluding other sites.

\section{TREATMENT}

Following the biopsy results, hysterectomy and removal of both masses with lymph node dissection was planned, as the masses were not locally invasive and had attainable margins. In light of her morbid obese body habitus, robot-assisted extrafascial total hysterectomy and bilateral salphingo-oopherectomy

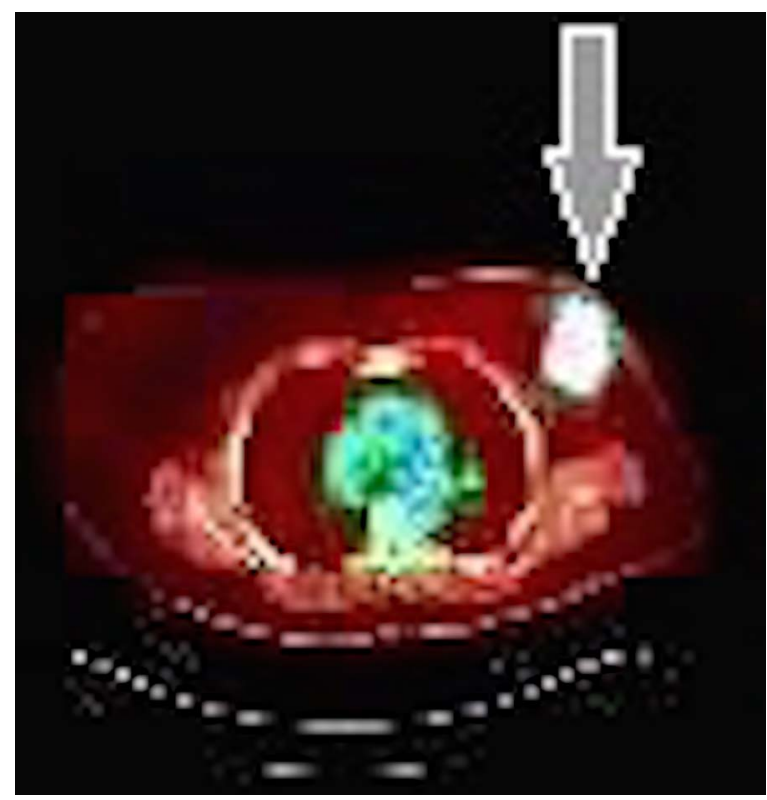

Figure 3 Axial view of whole body positron emission tomography scan depicting the breast mass.

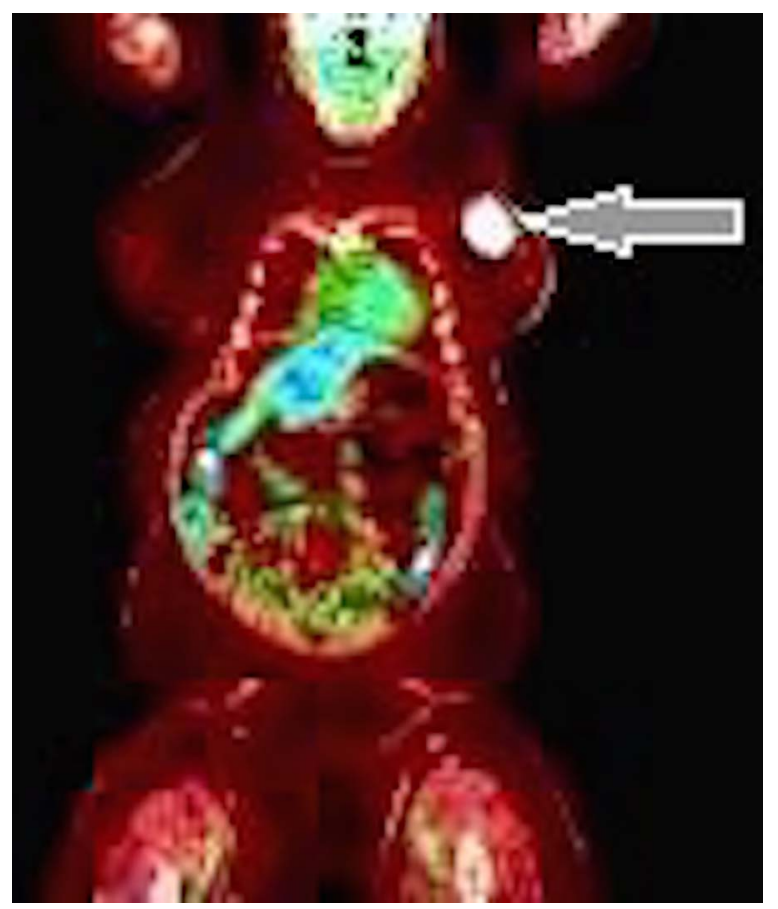

Figure 4 Coronal view of whole body positron emission tomography scan depicting the breast mass.

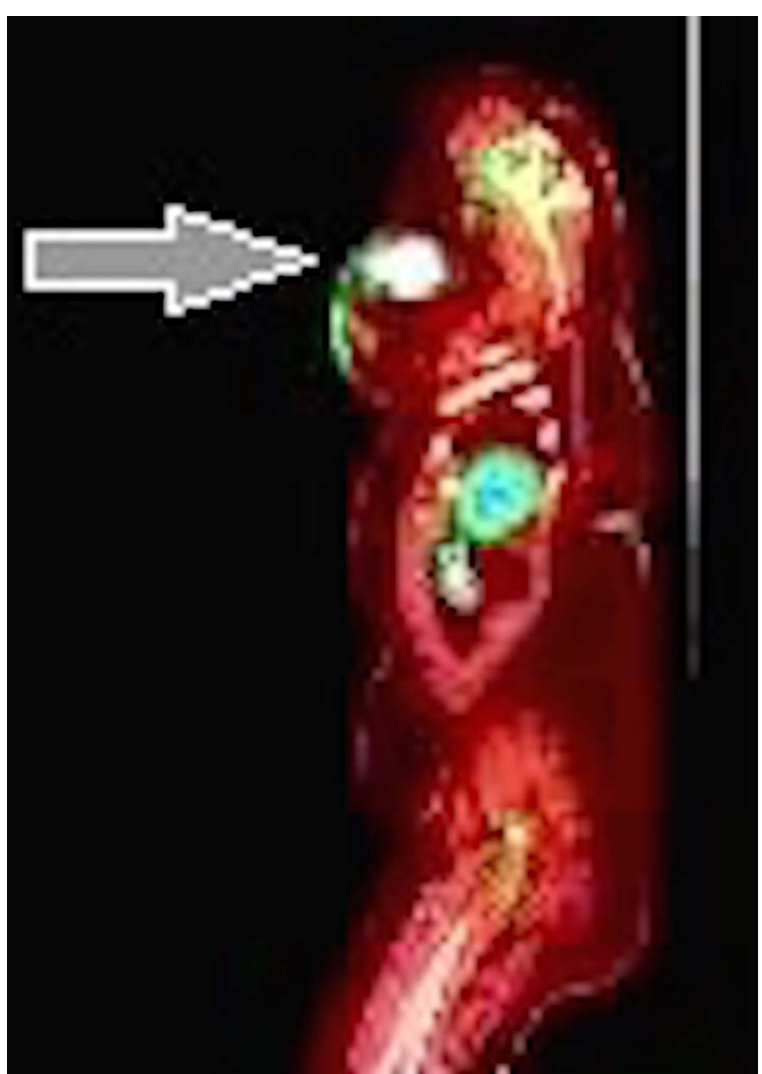

Figure 5 Sagittal view of whole body positron emission tomography scan depicting the breast mass.

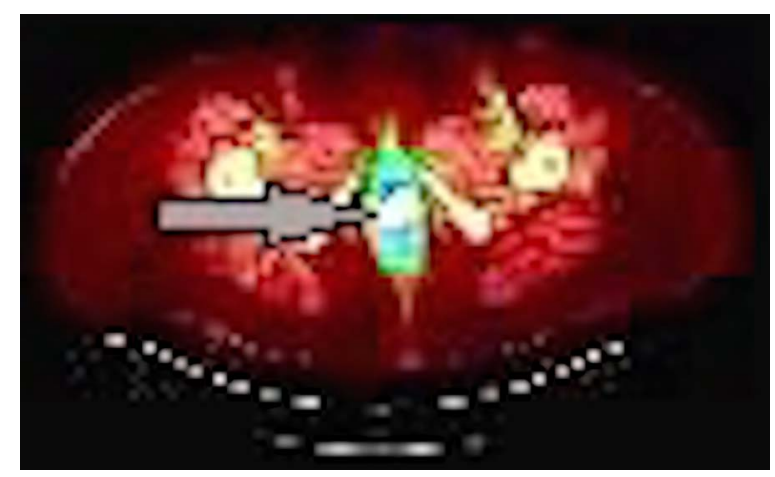

Figure 6 Axial view of whole body positron emission tomography scan depicting the vaginal mass.

with periaortic, external iliac nodes, and obturator lymph node dissections along with vaginal mass excision, and left partial breast mastectomy were performed. The axillary and inguinal lymph nodes were spared, as intraoperative frozen sections of sentinel axillary and inguinal lymph nodes were negative for malignancy. ${ }^{4} 5$

The uterus, ovaries and fallopian tubes were negative for malignancy. The vaginal mass was located in the distal aspect of the vagina with clear $1 \mathrm{~cm}$ margins. It measured $3 \mathrm{~cm}$ in its greatest dimension, and histologically demonstrated a poorly differentiated invasive SCC. The left breast mass was solid, smooth and well circumscribed, measuring $5 \mathrm{~cm}$ in greatest dimension with $1 \mathrm{~cm}$ clear margins. It also demonstrated a poorly differentiated SCC. Both masses had identical 


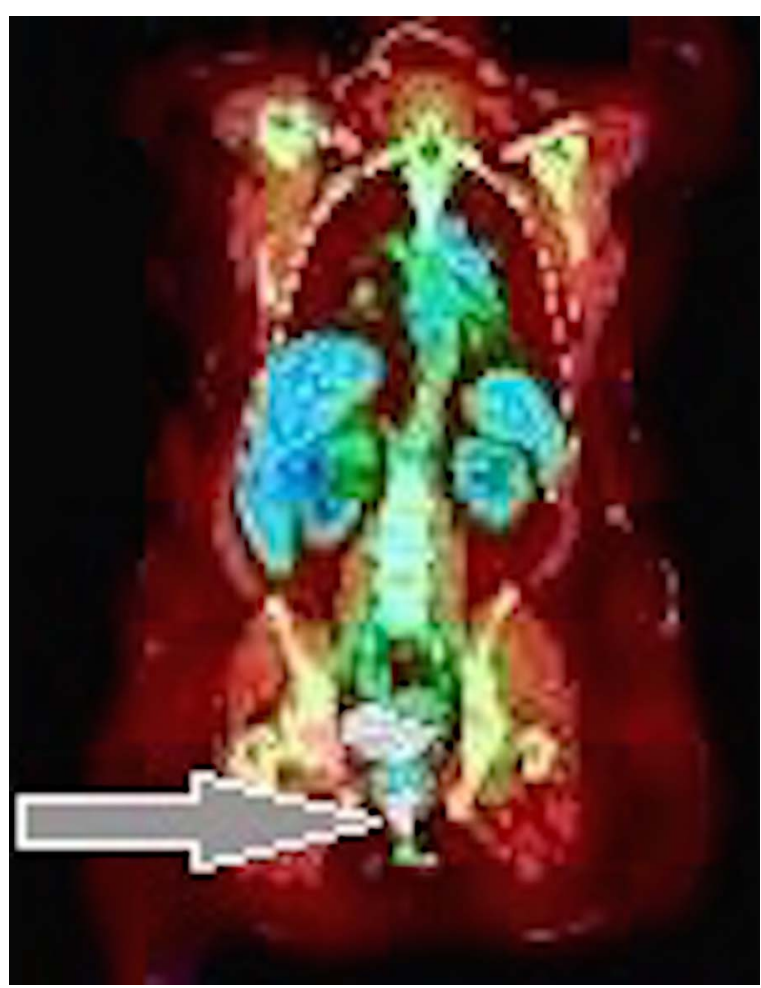

Figure 7 Coronal view of whole body positron emission tomography scan depicting the vaginal mass.

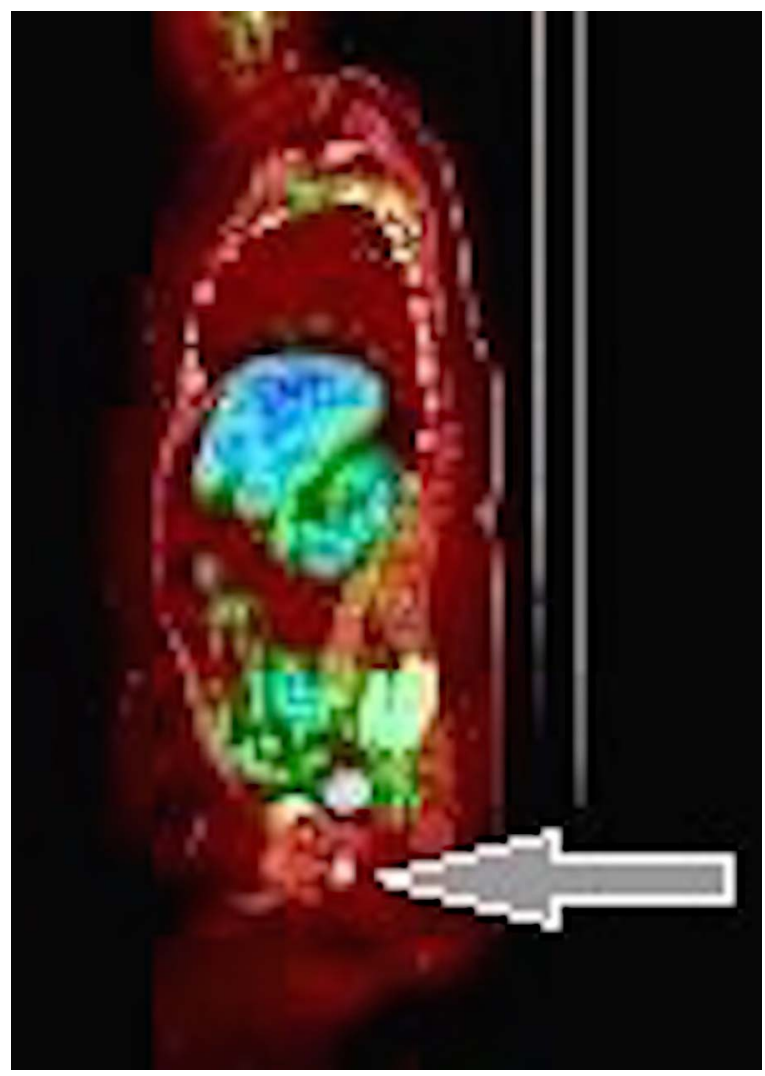

Figure 8 Sagittal view of whole body positron emission tomography scan depicting the breast mass.

morphologies. The breast was favoured to be a haematogenous metastasis from the primary vaginal mass, as it consisted of pure squamous cells without heterogeneity, no evidence of lymph node involvement and demonstrated HPV positivity.
The final diagnosis was primary vaginal carcinoma stage IVB, ${ }^{6}$ with metastasis to left breast. She was initially planned for five cycles of carboplatin area under curve (AUC) $5 \mathrm{mg} / \mathrm{mL} / \mathrm{min}$ monotherapy, as it carries a lower nephrotoxic profile compared to other agents. Cisplatin was not considered in light of preexisting renal insufficiency from diabetes (creatinine: $2.4 \mathrm{mg}$ / $\mathrm{dL}$ ). She only received four of five cycles every 3 weeks, as she become very weak and developed and intractable vomiting and diarrhoea. One month following chemotherapy, she received 10 treatments of $50 \mathrm{~Gy}$ of pelvic external beam radiation therapy, 3 treatments of $10 \mathrm{~Gy}$ of brachytherapy and 10 treatments of 50 Gy of breast radiation.

\section{OUTCOME AND FOLLOW-UP}

She was carefully followed every 3 months for 2 years, then every 3-6 months afterwards with physical examinations, mammograms, pap smears and PET scans, all of which were negative throughout the course of 3 years. Presently, she remains cancerfree without any recurrences.

\section{DISCUSSION}

Vaginal cancer accounts for 1-2\% of all gynaecological malignancies. ${ }^{1}$ The majority of vaginal tumours occur as a direct extension from primary cervical carcinoma, vulvar carcinomas or metastasis from other sites. ${ }^{7}$ Systemic spread of vaginal carcinoma to other organs usually occurs haematogenously. ${ }^{7}$ In this case, there was a $3 \mathrm{~cm}$ clear margin that was free of invasion between the cervix and distal vagina, hence proving that the vagina was the origin. Cervical cancer and endometrial cancer were ruled out, as the pap smear and endometrial biopsy were negative for malignancy. Although the IHC studies of the vaginal mass and breast mass demonstrated HPV positivity, this was not identified on the pap smear, as the location the mass was more distal to the cervix.

A notable feature is the distinct difference in size of the vaginal mass and breast mass. Typically, SCC of the vagina is very slow growing. Like cervical cancer, vaginal cancer usually forms overtime from a precancerous vaginal intraepithelial neoplasia (VAIN). ${ }^{7}$ This was evident in our patient, as the vaginal mass and breast mass were HPV positive, which is indeed associated with the development of precancerous VAIN. The HPV subtype 16 , which she demonstrated positivity for, is extremely notorious for harbouring the highest malignant potential in the female genital tract. ${ }^{7}$ It is believed, since our patient did not seek gynaecological care for 15 years prior, that the premalignant VAIN had undergone malignant transformation to vaginal cancer. It is unlikely to have spontaneously grown within the past few months, as vaginal cancers grow slowly and result from a premalignant lesion, thus supporting it to be the primary metastatic origin.

During the early stages of malignant transformation in the vaginal mass, it is believed that the metastatic spread to the breast occurred haematogenously in this case. Compared to vaginal cancer, breast cancer is more aggressively growing, with reported rates of rapid growth within 25-76 days. ${ }^{9}$ This makes it more likely that the breast growth had increased substantially over the past few months, rather than the vaginal mass. The relation to left-sided laterality in this case is unclear. Generally, however, breast cancers are $5-10 \%$ more common on the left breasts than the right breast. ${ }^{10}$ Breast cancer usually spreads through lymphatic dissemination and is associated with a very poor prognosis. ${ }^{11}$ Haematogenous spread of breast cancer usually occurs through Batson's plexus areas linked with its vasculature, such as bone, brain, spine and lung. ${ }^{8} 12$ It is unlikely 
that the breast mass was the primary source for the haematogenous spread of cancer due to the unrelated vasculature to the vagina.

The treatment for this malignancy was very challenging, as no randomised trials exist for definitive management. Usually for stage IVB vaginal cancer, radiation is the preferred therapy. ${ }^{7}$ In this case, surgical removal was performed first, as the masses were not locally invasive and did not require radiation to shrink them. The decision for hysterectomy, bilateral salphingooopherectomy and removal of the cervix was made to prevent further postmenopausal bleeding, prevent local invasion of vaginal tumour and for pathological assessment of possible tumour invasion.

After surgery, adjuvant chemotherapy with carboplatin alone was administered prior to radiation therapy to target the systemic disease. According to National Comprehensive Cancer Network (NCCN) guidelines, cisplatin is preferred for cervical cancer and also recommended for vaginal cancer. ${ }^{13}$ However, cisplatin was not the optimal choice in our patient in light of her multiple comorbidities, particularly renal failure from diabetic nephropathy; and high side effect profile of this chemotherapeutic agent. ${ }^{14}$ Usually, a regimen consisting of paclitaxel prior to carboplatin is often administered for cervical cancer. ${ }^{13} 15$ In our patient, however, carboplatin used alone was felt to be effective in treating this malignancy. She received only

\section{Patient's perspective}

When I first received my diagnosis I was shocked; not because of the diagnosis as I felt the lump in my breast, bled and went to the emergency room; but because it was stage IV cancer. From my understanding, I know stage IV is very critical. I felt whatever is going to happen will happen. I never cried over it and I did not think about it. I took it one step at a time and thought, 'let me have my operation and if it works out then good, if it does not then as long as I have some time to spend with my family, I will accept whatever is to come.

I underwent aggressive chemotherapy with injections every 3 weeks. My body became very weak and eventually felt like it shutdown. By the fourth treatment, I felt extremely sick; not sick from vomiting, rather extremely weak and exhausted. A month later, I underwent radiation therapy. This was indeed the absolute worst. I had a total of 23 radiation treatments, 10 on my breast, 10 on my pelvic region, both externally. The most painful and worse was the internal radiation, for which I underwent three treatments. I became aggravated, as I noticed my bowel movements changed and my insides were fried. I felt like a totally changed person. After 3 years though, I am starting to feel much better about it. I even gained back all the weight I had lost from chemotherapy.

Every physician who provided care for me was absolutely fantastic. The gynaecological oncologist did an amazing job and I still visit her regularly every 6 months. The breast surgeon also did a great job, and has been encouraging me to get my right breast reduced to the size of the left breast. The oncologist has been great and sets everything up in terms of laboratory work and positron emission tomography scans and visits every 3 months for check-up. I do not think I would have made it if I did not have their supportive care and treatment. four of six cycles of carboplatin as she developed intractable vomiting and diarrhoea, which is a common side effect of carboplatin. $^{16}$

There are very few case reports describing pure SCC of the breast occurring as a metastasis from sources such as the uterus, hand and vulva. ${ }^{17-21}$ However, no cases of SCC breast emerging from the vagina were found to the best of our knowledge. One study by Menes et $a l^{22}$ stated that most authors recommend treating SCC of the breast according to the guidelines for treatment of infiltrating ductal carcinoma; suggesting a combined regimen with 5 -flurouracil, cisplatin and adriamycin. ${ }^{23}$ Carboplatin is typically administered in addition to multidrug chemotherapy regimens for triple negative breast cancer. ${ }^{23}$ In this case, our patient's malignancy responded to an initial regimen of carboplatin alone, which is certainly unusual and favours the vaginal mass to indeed have been the primary origin of malignancy.

Presently, the patient continues to maintain complete remission of cancer without recurrences. This case demonstrates a novel and unique metastasis of primary vaginal cancer with dissemination to the breast. Our patient exhibited an optimal response to chemotherapy with carboplatin alone. Although vaginal cancer is extremely rare, larger studies should be conducted to further validate the role of this monotherapy, as combined chemotherapy regimens carry higher side effect profiles and are extremely costly. Studies evaluating the role of bevacizumab in vaginal cancer, which was recently approved by the Federal Drug Administration (FDA) in 2014 for cervical cancer, should be studied for patients with vaginal carcinoma. ${ }^{24}$

\section{Learning points}

- This is a unique and novel case of vaginal cancer metastasising to the breast through haematogenous spread.

- The breast mass was favoured to be a metastasis of the primary vaginal mass, as it consisted of pure squamous cell elements, human papilloma virus positivity, negative axillary nodal involvement and was more rapidly growing than the vaginal mass.

- Normally advanced stage IVB vaginal cancer is treated with radiation. However, hysterectomy and surgical excision of both masses was performed, as the tumours were not locally invasive and had attainable margins.

- Our patient exhibited an optimal response to chemotherapy with carboplatin alone, which is very unusual as cisplatin with paclitaxel is preferred for this type of malignancy.

- Although vaginal cancer is extremely rare, larger studies are warranted to better understand the role of carboplatin chemotherapy alone for vaginal cancer, as it is cost-effective and spares numerous side effects associated with combined regimens.

Acknowledgements The authors would like to acknowledge Vasanthi Chandrasekaran MD, Neena Chandrasekaran MD, Siva Pani PhD and Mindy Bohrer MD for their support in this endeavour.

Competing interests None declared.

Patient consent Obtained.

Provenance and peer review Not commissioned; externally peer reviewed.

\section{REFERENCES}

1 Seigal RI, Miller KD, Jemal A. Cancer statistics, 2015. CA Cancer J Clin 2015;65:5-29.

2 Creasman WT. Vaginal cancers. Curr Opin Obstet Gynecol 2005;17:71-6. 
3 Dunn LJ, Napier JG. Primary carcinoma of the vagina. Am J Obstet Gynecol 1996;96:1112-16.

4 Krag DN, Anderson SJ, Julian TB, et al. Sentinel-lymph-node resection compared with conventional axillary-lymph-node dissection in clinically node-negative patients with breast cancer: overall survival findings from the NSABP B-32 randomised phase 3 trial. Lancet Oncol 2010;11:927-33.

5 Brunner $\mathrm{AH}$, Polterauer $\mathrm{S}$, Tempfer $\mathrm{C}$, et al. The accuracy of intraoperative frozen section of the inguinal sentinel lymph node in vulvar cancer. Anticancer Res 2008;28:4091-4

6 Pecorelli S. New FIGO staging for carcinoma of vulva, cervix, endometrium, and sarcomas. Int J Gynaecol Obstet 2005;105:19367689.

7 Dizon D, Campos S. Dx/Rx: Gynecologic Cancer. Sadbury, Massachusetts: Jones and Bartlett Publishers, 2011.

8 Maccauro G, Spinelli MS, Mauro S, et al. Physiopathology of spine metastasis. Int J Surg Oncol 2011;2011:1-8.

9 Pearlman AW. Breast cancer-influence of growth rate on prognosis and treatment evaluation. Cancer 1975;38:1826-33.

10 Wilting J, Hagedorn M. Left-right asymmetry in embryonic development and breast cancer: common molecular determinants. Curr Med Chem 2011;18:5519-27.

11 Bundred NJ. Prognostic and predictive factors in breast cancer. Cancer Treat Rev 2001;51:434-43.

12 Ross JS, Slodkowska E. Circulating and disseminated tumor cells in the management of breast cancer. Am J Clin Pathol 2009;132:237-45.

13 National Comprehensive Cancer Network. NCCN-National Comprehensive Cancer Network. 2014. http://www.nccn.org/

14 Ozols RF, Bundy BN, Greer BE, et al. Phase III trial of carboplatin and paclitaxel compared with cisplatin and paclitaxel in patients with optimally resected stage III ovarian cancer: a Gynecologic Oncology Group study. J Clin Oncol 2003:21:3194-200.

15 Xiong X, Fan W, Kraft AS. Cell cycle dependent antagonistic interactions between paclitaxel and carboplatin in combination therapy. Cancer Biol Ther 2007;6:1067-73.

16 Boussios S, Pentheroudakis G, Katsanos K, et al. Systemic treatment-induced gastrointestinal toxicity: incidence, clinical presentation and management. Ann Gastroenterol 2012;25:106-18.

17 Samant R, Lau B, E C, et al. Primary vaginal cancer treated with concurrent chemoradiation using Cis-platinum. Int J Radiat Oncol Biol Phys 2007:69:746-50.

18 Yordanov Y, Dimitrova P. Breast metastasis of a squamous cell carcinoma of the uterine cervix: a case report. Akush Ginekol (Sofiia) 2015;54:38-43.

19 Aitelhaj M, Khoyaali SL, Boukir A, et al. Breast and splenic metastases of squamous cell carcinoma from the uterine cervix: a case report. J Med Case Rep 2014;8:359.

20 Galyfos G, Karantzikos G, Sainou A, et al. Squamous cell carcinoma of the hand metastasized to the breast: a unique case. Breast Dis 2014:34:169-72.

21 Verfaillie G, Garbar C, Vanhoeji M, et al. Metastasis of vulvar cancer in the breast. Acta Chir Belg 2012;112:444-6.

22 Menes T, Schachter J, Morgenstern $S$, et al. Primary squamous cell carcinoma of the breast. Am J Clin Oncol 2013;37:867-73.

23 Von Minckwitz G, Schneeweiss A, Loibl S, et al. Neoadjuvant carboplatin in patient with triple-negative and HER2-positive early breast cancer (GeparSixto; GBG 66): a randomised phase 2 trial. Lancet Oncol 2014;15:747-56.

24 FDA approves Avastin (bevacizumab) to treat patients with aggressive and late-stage cervical cancer. 2014;Aug 14. http://www.fda.gov/NewsEvents/Newsroom/ PressAnnouncements/ucm410121.htm

Copyright 2016 BMJ Publishing Group. All rights reserved. For permission to reuse any of this content visit http://group.bmj.com/group/rights-licensing/permissions.

BMJ Case Report Fellows may re-use this article for personal use and teaching without any further permission.

Become a Fellow of BMJ Case Reports today and you can:

- Submit as many cases as you like

- Enjoy fast sympathetic peer review and rapid publication of accepted articles

- Access all the published articles

- Re-use any of the published material for personal use and teaching without further permission

For information on Institutional Fellowships contact consortiasales@bmjgroup.com

Visit casereports.bmj.com for more articles like this and to become a Fellow 